\title{
The Social Phobia Psychotherapy Research Network
}

\author{
The First Multicenter Randomized Controlled Trial of Psychotherapy for Social Phobia: \\ Rationale, Methods and Patient Characteristics
}

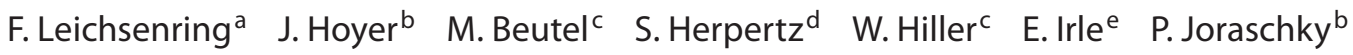 \\ H.H. König ${ }^{f}$ T.M. de Liz ${ }^{g}$ B. Nolting ${ }^{d} \quad$ K. Pöhlmann ${ }^{b} \quad$ S. Salzer ${ }^{\text {e H. Schauenburg }}{ }^{\text {h }}$ \\ U. Stangierg $^{g} \quad$ B. Strauss ${ }^{g} \quad$ C. Subic-Wrana ${ }^{c} \quad$ S. Vormfelde ${ }^{e} \quad$ G. Weniger ${ }^{e} \quad$ U. Willutzki ${ }^{i}$ \\ J. Wiltink ${ }^{c}$ E. Leibing ${ }^{\mathrm{e}}$ \\ a University of Giessen, Giessen, b University of Dresden, Dresden, 'University of Mainz, Mainz, \\ dUniversity of Dortmund, Dortmund, e University of Göttingen, Göttingen, fUniversity of Leipzig, Leipzig, \\ gUniversity of Jena, Jena, ' 'University of Heidelberg, Heidelberg, 'University of Bochum, Bochum, Germany
}

\section{Key Words}

Social phobia $\cdot$ Cognitive-behavioral therapy .

Psychodynamic psychotherapy · Attachment $\cdot$ Genetics .

Neuroimaging $\cdot$ Cost-effectiveness

\begin{abstract}
This paper presents the Social Phobia Psychotherapy Research Network. The research program encompasses a coordinated group of studies adopting a standard protocol and an agreed-on set of standardized measures for the assessment and treatment of social phobia (SP). In the central project (study A), a multicenter randomized controlled trial, refined models of manualized cognitive-behavioral therapy and manualized short-term psychodynamic psychotherapy are compared in the treatment of SP. A sample of 512 outpatients will be randomized to either cognitive-behavioral therapy, short-term psychodynamic psychotherapy or waiting list. Assessments will be made at baseline, at the end of treatment and 6 and 12 months after the end of treatment. For quality assurance and treatment integrity, a specific project using highly elaborated measures has been established
\end{abstract}

(project Q). Study A is complemented by 4 interrelated add-on projects focusing on attachment style (study B1), on cost-effectiveness (study B2), on variation in the serotonin transporter gene in SP (study C1) and on structural and functional deviations of the hippocampus and amygdala (study C2). Thus, the Social Phobia Psychotherapy Research Network program enables a highly interdisciplinary research into SP. The unique sample size achieved by the multicenter approach allows for studies of subgroups (e.g. comorbid disorders, isolated vs. generalized SP), of responders and nonresponders of each treatment approach, for generalization of results and for a sufficient power to detect differences between treatments. Psychological and biological parameters will be related to treatment outcome, and variables for differential treatment indication will be gained. Thus, the results provided by the network may have an important impact on the treatment of SP and on the development of treatment guidelines for SP.

Copyright $\odot 2008$ S. Karger AG, Basel

\section{KARGER}

Fax +4161306 1234

E-Mail karger@karger.ch

www.karger.com (c) 2008 S. Karger AG, Basel

0033-3190/09/0781-0035\$26.00/0

Accessible online at:

www.karger.com/pps
Prof. Dr. Falk Leichsenring

Department of Psychosomatic Medicine and Psychotherapy, University of Giessen

Ludwigstrasse 76, DE-35392 Giessen (Germany)

Tel. +49641994 5660, Fax +496419945661

E-Mail Falk.Leichsenring@psycho.med.uni-giessen.de 


\section{Introduction}

In order to fill specific lacks in international psychotherapy research, the Ministry of Education and Research of Germany has set up a research program ${ }^{1}$. A committee of international experts in psychotherapy research recommended the Social Phobia Psychotherapy Research Network (SOPHO-NET) for funding ${ }^{2}$. This article introduces the SOPHO-NET research program ${ }^{3}$.

Social phobia (SP) is a frequent, chronic and severely impairing mental disorder [1-4]. Although the available treatments proved to be beneficial for SP [5-11], the rates of treatment responders are not yet satisfactory $[5,10,11]$. Furthermore, the neurobiological basis of SP has received only limited investigation [12-14]. Thus, further studies addressing both the efficacy of psychotherapy in SP and its neurobiology are required.

The research program of the SOPHO-NET ${ }^{4}$ encompasses a coordinated group of studies adopting a standard protocol and an agreed-on set of standardized measures for the assessment and treatment of SP. In addition to the scientific projects, a specific unit (Q) has been established for project management and quality assurance (principal investigator: Dr. Leibing, Göttingen). Q cooperates closely with institutions specialized for data management and project management. The network includes highly interdisciplinary and interrelated research projects. For the first time [15], manualized cognitive-behavioral therapy (CBT) and manualized short-term psychodynamic psychotherapy (STPP) are compared in a largescale multicenter study of SP (study A). By highly elaborated measures, investigator allegiance effects are controlled for (see below). The unique sample size ( $\mathrm{n}=$ 512) achieved by the multicenter approach will allow for subgroup analyses (e.g. comorbid disorders), for the identification of responders and nonresponders of each treatment approach, for a sufficient power to detect differences between treatments and for generalization of results. Psychological, genetic, neural and health economic parameters will be related to treatment outcome, and variables for differential treatment indication will be gained.

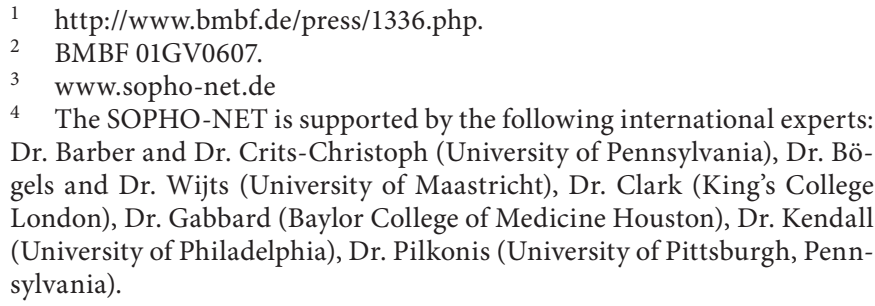
Dr. Barber and Dr. Crits-Christoph (University of Pennsylvania), Dr. Bögels and Dr. Wijts (University of Maastricht), Dr. Clark (King's College London), Dr. Gabbard (Baylor College of Medicine Houston), Dr. Kendall (University of Philadelphia), Dr. Pilkonis (University of Pittsburgh, Pennsylvania).

Thus, the results provided by the network may have an important impact on the treatment of SP and on the development of treatment guidelines.

\section{Methods and Description of the Network Projects}

In the following, the research projects presently carried out by the SOPHO-NET will be described. The focus will be on the randomized controlled treatment study (study A).

Design of the Multicenter Treatment Study $A^{5}$

For future studies of SP, experts in the field recommended a multicenter approach [16]. Study A is a randomized controlled multicenter study comparing STPP and CBT under equal conditions in the treatment of SP (principal investigator of study A: Dr. Leichsenring, Giessen). As an additional control condition, a waiting list group is included. Five research sites participate in the trial (Universities of Bochum/Dortmund, Dresden, Göttingen, Jena and Mainz). In order to ensure a sufficient power, a total of 512 patients will be randomized to 1 of the 3 conditions (fig. 1).

\section{Patient Inclusion and Exclusion Criteria}

The following inclusion criteria are applied: diagnosis of SP (SCID I) and Liebowitz Social Anxiety Scale score $>30$ [17], as well as age: $18-59$ and 60-70 years (allowing to test for effects of age). SP must be the primary diagnosis, i.e. the severest disorder according to ADIS-IV rating $[18,19]$. By including comorbid disorders - provided that SP is the severest disorder - a clinically representative sample will be gained, allowing to analyze the impact of comorbid disorders on the outcome. A rate of $60 \%$ of women will be included, reflecting the high prevalence of SP in women [2]. The following conditions are excluded from the trial: psychotic disorders, prominent risk of self-harm, acute substancerelated disorders, personality disorders except for avoidant, obsessive-compulsive or dependent personality disorder (as assessed by SCID-II); organic mental disorder; severe medical conditions; concurrent psychotherapeutic or psychopharmacological treatment.

\section{Assessment}

Assessments are carried out at baseline, and in weeks 8,15 and 25 (after treatment). This procedure is analogous to Davidson et al. [11]. The primary endpoints are in week 25 (after treatment) and 6 and 12 months after the end of treatment. Assessments in weeks 8 and 15 ensure intent-to-treat analyses. As studies of longterm effects in SP are scant [20], follow-up studies will be carried out not only 6 months but also 12 months after termination of treatment (consistent with EMEA guidelines ${ }^{6}$ ). The assessment instruments and their purposes are described in table 1. For quality assurance, all diagnostic sessions will be videotaped. The interrater reliability for all observer-rated instruments will be carefully controlled. For the self-report instruments used in the study, sufficient psychometric properties have been demonstrated (see references in table 1 ).

www.controlled-trials.com/ISRCTN53517394.

www.emea.eu.int/pdfs/human /ewp/363503en.pdf. 
Fig. 1. Consort flowchart of the SOPHONET treatment study A.

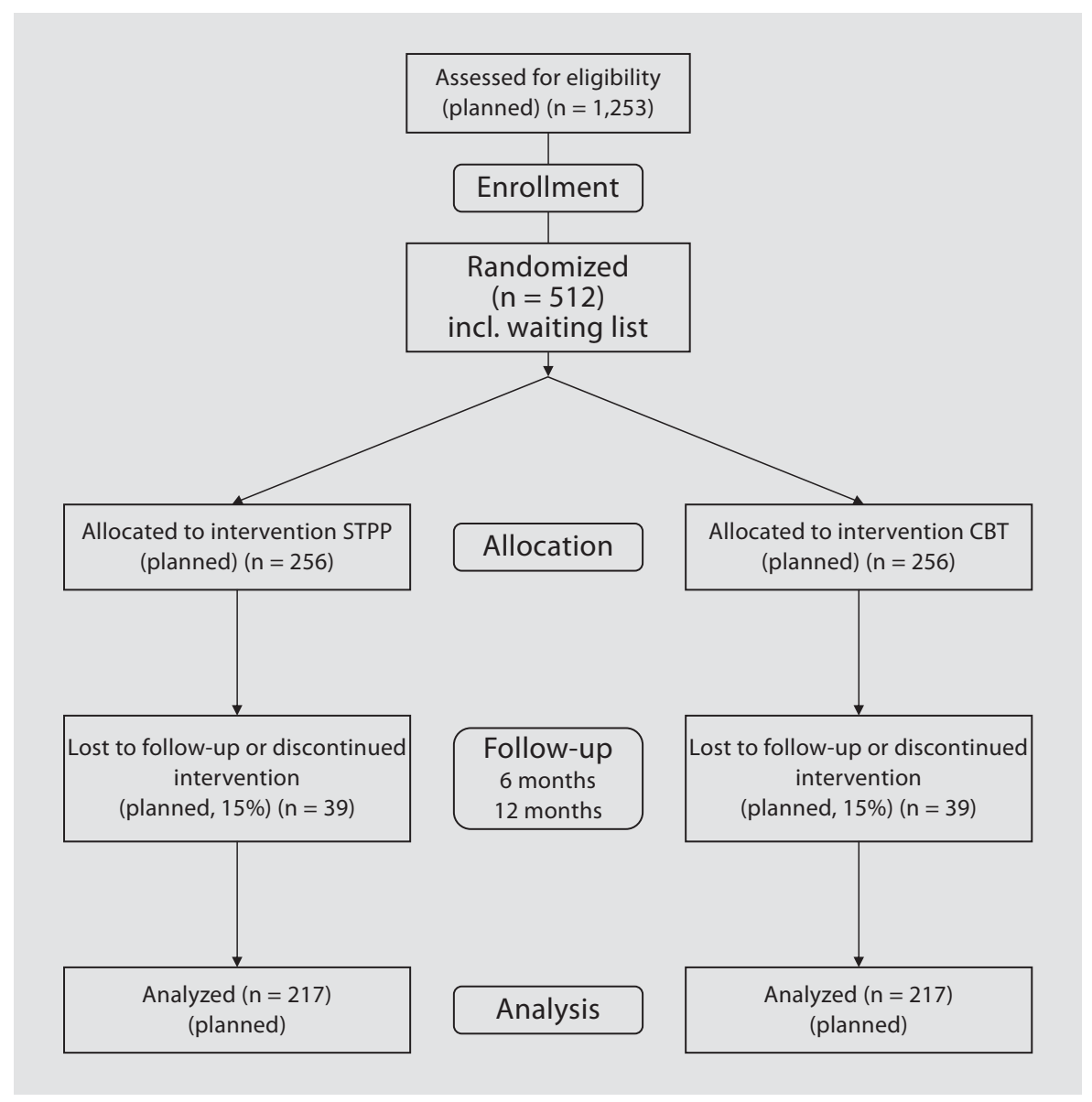

Sample Sizes and Power Calculations for Study A

In order to detect even a small difference between CBT and STPP, which corresponds to a difference in response rates of $15 \%$ $(h=0.30)[21], 217$ patients are required in each treatment group to achieve a statistical power of 0.90 at $\alpha=0.05$ using a 2-tailed test. The dropout rates of psychotherapy studies of SP range from $9.2 \%$ [22] to $28 \%$ [11], with a mean dropout rate of $15 \%$. At a dropout rate of $15 \%$, a total sample of 512 patients is required to ensure a high statistical power.

\section{Patient Recruitment}

All of the participating centers run well-established outpatient clinics. Patients will be recruited by these institutions. Information about SP and the SOPHO-NET research projects will be published by the mass media in order to recruit a sufficient number of patients.

\section{Treatments Applied in Study A}

CBT and STPP are the methods most frequently applied in clinical practice to treat anxiety disorders [23]. As the response rates of the available treatments are not yet sufficient, further research is required. Experts in the field suggest that the response rates may be improved by longer and more intensive treatment [5]. Thus, in the present study up to 30 sessions of CBT or STPP are carried out. The CBT applied in the present study is based on
Clark's Cognitive Therapy [24], which was shown to be efficacious in several trials $[8,10,25]$. This approach differs in some essential components from the program designed by Heimberg et al. [26], which is currently one of the best supported psychotherapeutic treatments for SP. Clark and Wells' [24] approach has a wider range of therapeutic procedures, all of which explicitly focus on reversing the maintaining processes specified in their model [27]. This approach includes the following steps: (1) an individual version of the Clark and Wells model is derived along with the patient. It serves as a point of reference during the treatment; (2) key safety behaviors are identified and their dysfunctional effects are demonstrated with an experiential exercise in which patients role-play difficult social situations while focusing attention on themselves and using their safety behaviors and then focusing attention externally and attempt to drop their safety behaviors; (3) patients are trained to focus their attention externally, to reduce their dysfunctional self-monitoring and to obtain more accurate information on how they are responded to by others; (4) videofeedback is applied to demonstrate the discrepancy between their distorted self-images and their actual social performance; (5) extensive use of behavioral experiments is made in which patients specify their feared outcomes for various social situations and then test out whether they occurred during planned exposure, and (6) problematic anticipatory or postevent processing is identified and modified, and dysfunctional assumptions are 
Table 1. Assessment instruments and time of assessment of study A and study B2

\begin{tabular}{|c|c|c|c|c|c|c|c|c|}
\hline Purpose & Domain & Instrument & Perspective & Screening & $\begin{array}{l}\text { Before } \\
\text { treatment }\end{array}$ & $\begin{array}{l}8 \text { and } \\
15 \text { weeks }\end{array}$ & $\begin{array}{l}\text { After } \\
\text { treatment }\end{array}$ & $\begin{array}{l}\text { 6-/12-month } \\
\text { follow-up }\end{array}$ \\
\hline \multirow[t]{3}{*}{ Screening } & & SCID I, II & Independent rater & $\mathrm{x}$ & & & & \\
\hline & & ADIS-IV rating & Independent rater & $\mathrm{x}$ & & $\mathrm{x}$ & $\mathrm{x}$ & $\mathrm{x}$ \\
\hline & & LSAS & Independent rater & $\mathrm{x}$ & & & & \\
\hline \multirow[t]{9}{*}{ Outcome } & $\begin{array}{c}\text { Social phobia } \\
\text { diagnosis }\end{array}$ & SCID I & Independent rater & & $\mathrm{x}$ & $\mathrm{x}$ & $\mathrm{x}$ & $\mathrm{x}$ \\
\hline & $\begin{array}{l}\text { Social phobia } \\
\text { symptoms }\end{array}$ & $\begin{array}{l}\text { LSAS primary } \\
\text { outcome measure }\end{array}$ & Independent rater & & $\mathrm{x}$ & $\mathrm{x}$ & $\mathrm{x}$ & $\mathrm{x}$ \\
\hline & $\begin{array}{l}\text { Social phobia } \\
\text { symptoms }\end{array}$ & SPAI & Patient & & $\mathrm{x}$ & & $\mathrm{x}$ & $\mathrm{x}$ \\
\hline & $\begin{array}{l}\text { Interpersonal } \\
\text { functioning }\end{array}$ & IIP & Patient & & $\mathrm{x}$ & & $\mathrm{x}$ & $\mathrm{x}$ \\
\hline & Self-concept & FSKN & Patient & & $\mathrm{x}$ & & $\mathrm{x}$ & $\mathrm{x}$ \\
\hline & Depression & BDI & Patient & & $\mathrm{x}$ & & $\mathrm{x}$ & $\mathrm{x}$ \\
\hline & Shame & TOSCA & Patient & & $\mathrm{x}$ & & $\mathrm{x}$ & $\mathrm{x}$ \\
\hline & Costs & CSSRI & Patient & & $\mathrm{x}$ & & $\mathrm{x}$ & $\mathrm{x}$ \\
\hline & $\begin{array}{l}\text { Utilities/quality } \\
\text { of life }\end{array}$ & $\begin{array}{l}\text { EQ-5D, } \\
\text { SF-12/SF-6 D }\end{array}$ & Patient & & $\mathrm{x}$ & & $\mathrm{x}$ & $\mathrm{x}$ \\
\hline \multirow[t]{4}{*}{ Process } & Helping alliance & HAQ & Patient & & & $\mathrm{x}$ & $\mathrm{x}$ & \\
\hline & Treatment integrity & PACS-SE & Patient & & & & $\mathrm{x}$ & \\
\hline & Conflicts & CCRT & Independent rater & & \multirow{2}{*}{\multicolumn{4}{|c|}{$\begin{array}{l}\text { sessions } 3 \text { and } 5 \text { vs. } 17 \text { and } 18 \\
\text { randomly selected sessions }\end{array}$}} \\
\hline & $\begin{array}{l}\text { Adherence and } \\
\text { competence }\end{array}$ & $\begin{array}{l}\text { PACS-SE, } \\
\text { CTACS }\end{array}$ & Independent rater & & & & & \\
\hline
\end{tabular}

ADIS-IV = Anxiety Disorders Interview Schedule Adult Version (rating scale for severity of symptoms) [18, 19]; BDI = Beck Depression Inventory [41]; CCRT = Core Conflictual Relationship Theme Method [28, 30]; CSSRI = Client Sociodemographic and Service Receipt Inventory [42, 43]; CTACS = Cognitive Therapy Adherence and Competence Scale [35]; EQ-5D = EuroQol Questionnaire [44-46]; FSKN = Frankfurter Selbstkonzept-Skalen (Frankfurt Self-Concept Scales) [47]; HAQ = Helping Alliance Questionnaire [48]; IIP = Inventory of Interpersonal Problems [49]; LSAS = Liebowitz Social Anxiety Scale [50]; PACS-SE = Penn Adherence and Competence Scale for SET [28, 36]; SCID I = Structured Clinical Interview for DSM-IV Axis I Disorders [51]; SCID II = Structured Clinical Interview for DSM-IV Axis II Disorders [51]; SF-12/SF-6 D = Fragebogen zum Gesundheitszustand (Quality of Life Questionnaire) $[52,53]$; SPAI = Social Phobia and Anxiety Inventory [54, 55]; TOSCA = Test of Self-Conscious Affects [56, 57].

modified by behavioral experiments and cognitive restructuring. With regard to psychodynamic therapy, 2 studies demonstrated the efficacy of STPP in the treatment of SP $[6,9]$. However, in these studies the sample size was small or no treatment manual was used for STPP. In the present study, a treatment manual for STPP that is based on Luborsky's Supportive-Expressive Therapy (SET) [28] will be used. SET is among the empirically best supported manualized models of STPP [29]. SET focuses on the 'Core Conflictual Relationship Theme' (CCRT) [28, 30]. A CCRT consists of 3 components: a wish (W), a response from the others (RO) and a response from the self (RS). In this scheme, RS represents the patient's symptoms, e.g. SP. For a patient with SP, the CCRT could be, for example: 'I wish to be approved of by others (W). However, the others will humiliate me (RO). I feel ashamed and get afraid of meeting other people, so I have decided to avoid exposing myself' (RS, symptoms of SP). SET uses both supportive and expressive interventions. In SET the establishment of a helping alliance is a central aspect of supportive interventions [28]. Expressive (i.e. interpretive) interventions enhance the patient's cognitive and emotional understanding of his or her present symptoms and of the underlying CCRT [28]. In order to tailor SET specifically to the treatment of SP, the psychodynamic research group of the SOPHO-NET integrated specific principles for interventions derived from the psychodynamic models of SP [31, 32] into SET [33]. This SP-specific manual will be used in the present study. The SP-specific intervention principles include the following: (a) informing the patient about the disorder at the beginning of treatment; (b) establishing a secure positive therapeutic alliance to modify insecure attachments; (c) focusing on the affect of shame and point out its central role in SP; (d) encouraging the patient to actively confront rather than avoid the anxiety-producing situation; (e) supporting the patient in establishing a self-affirming inner dialogue; (f) exploring and discussing the use of psychotropic substances and medication used by many patients with SP to reduce anxiety, and (g) helping the patient improve social skills. Further interventions specific to the treatment of SP including, for example, the handling of counter-transference problems are described in the treatment manual [33]. Whereas the Clark and Wells approach has already been used in controlled studies and the CBT therapists of our study are already familiar 
with it, the STPP approach is based on a new manual. Thus, CBT is expected to be superior in the first $50 \%$ of the treated patients. In the second half of the treated patients, these differences are likely to decrease.

\section{Treatment Implementation and Treatment Integrity (Q)}

As mentioned above, a specific unit (Q) for project management and quality assurance has been developed. Within $\mathrm{Q}$, a special subunit has been established to ensure adequate and comparable treatment implementation in all trial sites as well as reliability of diagnostic assessments. Representatives of both CBT (Dr. Stangier) and STPP (Dr. Beutel) are responsible for adequate implementation of each approach. By this procedure, investigator allegiance effects are balanced between the 2 rival approaches and controlled for. A total of at least 20 therapists per treatment condition are included. In order to be accepted into the trial, therapists must have an advanced or completed clinical training of CBT or STPP, respectively. In both treatment conditions therapists receive equivalent manualized training and supervision [34]. Before treating study patients, therapist's competence is enhanced in a 20 -hour training program. During the trial, therapists receive group supervision by highly experienced and specifically trained local supervisors. Supervision is carried out every 2 weeks during the first 6 months of the treatment phase and monthly during the remaining 12 months. Adherence and competence for CBT is assessed by use of the Cognitive Therapy Adherence and Competence Scale (CTACS) [35], for STPP by use of the Penn Adherence and Competence Scale for Supportive-Expressive Therapy (PACS-SE) $[28,36]$. CTACS and PACS-SE are applied to videotaped therapy sessions. For that purpose, independent raters receive $60 \mathrm{~h}$ of training [37] following the training procedures by Barber and Crits-Christoph [38] for STPP and by Hill et al. [37] for CBT. Randomly selected videotapes will be used for interrater reliability assessment. To be included in the study, therapists have to demonstrate a sufficient level of competence in the treatment of at least 2 pilot cases before conducting actual trial therapies. Recommended by Dr. Barber, this therapist prerequisite relies on a cutoff value of $\geq 4$ in CTACS and PACS-SE, respectively, as a criterion for acceptable competence. During the trial, therapists are supported by continuous feedback given by the local trial site supervisors to prevent 'drifting'. Additionally, as a backup, the subunit responsible for treatment implementation will evaluate randomly selected videotapes of therapy sessions. Should the therapeutical quality fall below the 'red line', therapists will be given feedback. Those who fail to meet manualized standards will receive additional supervision. Should the therapists continue to provide less than adequate therapeutical performance, they will be withdrawn from the study. For the statistical evaluation of treatment integrity, PACS-SE and CTACS will be applied by blind raters to randomly drawn videotaped sessions. The 2 treatments are expected to differ significantly with regard to manualized treatment-specific interventions [39].

Add-On Projects of the Network

Study A is complemented by 4 add-on projects highly relevant to SP. For reasons of space limitations, the add-on projects will be described in more detail elsewhere. Project B1 examines the association between attachment style and treatment outcome (principal investigator: Dr. Strauss, Jena). Patients revealing a secure organized attachment are expected to achieve a better outcome than patients with insecure features and/or disorganized states of mind. Furthermore, self-reported attachment is likely to change after successful therapy, indicating increased security. In project B2, an economic evaluation of STPP and CBT will be conducted alongside the multicenter treatment study A. The direct and indirect costs, utilities, quality-adjusted life years and incremental cost-effectiveness ratios of the treatment strategies (STPP, CBT, waiting list) will be measured and compared (principal investigator: Dr. König, Leipzig). Project C1 explores the impact of genetic variation in the serotonin transporter gene on the severity of SP and on the outcome of psychotherapy (principal investigator: Dr. Vormfelde, Göttingen). The short allele and the S 10 allele are expected to predispose to severer symptoms of SP. The long allele and specifically the L 12 haplotype are predicted to be associated with a more favorable treatment outcome. In project $\mathrm{C} 2$, structural and functional abnormalities of amygdala and hippocampus in patients with SP are examined by neuroimaging including their possible therapy-induced changes after CBT or STPP, respectively (principal investigator: Dr. Irle, Göttingen). In study $\mathrm{C} 2$, both healthy control subjects and panic disorder patients serve as controls.

\section{Discussion}

The SOPHO-NET research plan presented here implements a number of methodological refinements that have previously been suggested. Among these methodological and substantial perspectives are the following: (a) establishing a specific unit for quality assurance, and for program and data management; (b) comparison of the psychotherapeutic treatments that are most common and relevant for clinical practice; (c) use of refined treatment models to improve responder rates; (d) highly elaborated measures to ensure treatment integrity; (e) methods against bias, in particular control for investigator allegiance effects (e.g. by co-investigatorship of experts in CBT and STPP, assurance of adherence and competence); (f) multicenter approach allowing for tests of generalizability and subgroup analyses (e.g. patients benefiting most and least from STPP or CBT; study of nonresponders); (g) inclusion of comorbid disorders to ensure clinically representative samples and to study the impact of comorbid disorders on outcome; (h) study of gender and developmental aspects (focus on women and elderly); (i) study of attachment styles as predictors of outcome; (j) inclusion of neurobiological research, and $(\mathrm{k})$ inclusion of cost-effectiveness analysis. In detail, the following hypotheses will be tested in the SOPHO-NET projects: with regard to the treatment study $\mathrm{A}$, the insufficient response rates reported in the presently available studies of SP are expected to be improved by a longer and more intensive treatment of up to 30 sessions. Differential effects are hy- 
pothesized: CBT is anticipated to be superior to STPP with regard to symptoms of SP, whereas STPP is expected to be superior with regard to improvements in self-image and interpersonal relationships. With regard to patient characteristics, subjects with secure attachment are likely to yield a better outcome than those insecurely attached (study B1). Functional and structural neural abnormalities found in patients with SP are hypothesized to normalize after treatment with CBT or STPP, respectively (study C2). Furthermore, specific genetic polymorphisms are expected to be associated with symptoms of SP (study C1). With regard to cost-effectiveness, the treatments are anticipated to pay off (B2). Thus, the SOPHO-NET research program can be expected to avoid shortcomings that contribute to the crisis of psychiatric research [40]. This research program is likely to yield important information for both the understanding and treatment of SP and for psychotherapy research in general.

\section{References}

1 Kessler RC: The impairments caused by social phobia in the general population: implications for intervention. Acta Psychiatr Scand 2003;108(suppl 417):19-27.

2 Alonso J, Angermeyer MC, Bernert S, et al: 12-Month comorbidity and associated factors in Europe: results from the European Study of the Epidemiology of Mental Disorders (ESEMeD) project. Acta Psychiatr Scand Suppl 2004;420:28-37.

3 Fehm L, Pelissolo A, Furmark T, Wittchen $\mathrm{HU}$ : Size and burden of social phobia in Europe. Eur Neuropsychopharmacol 2005; 15 : 453-462.

4 Keller MB: The lifelong course of social anxiety disorder: a clinical perspective. Acta Psychiatr Scand Suppl 2003;417:85-94.

5 Zaider TI, Heimberg RG: Non-pharmacologic treatments for social anxiety disorder. Acta Psychiatr Scand Suppl 2003;417:72-84.

6 Bögels S, Wijts P, Sallaerts S: Analytic psychotherapy versus cognitive-behavioral therapy for social phobia. EACBT, Prague, 2003.

7 Clark DM, Ehlers A, McManus F, Hackmann A, Fennel M, Campbell H, Flower T, Davenport C, Louis B: Cognitive therapy versus fluoxetine in generalized social phobia: a randomized placebo-controlled trial. J Consult Clin Psychol 2003;71:1058-1067.

8 Clark DM, Ehlers A, Hackmann A, McManus F, Fennel M: Cognitive therapy versus exposure and applied relaxation in social phobia: a randomized controlled trial. J Consult Clin Psychol 2006;74:568-578.

9 Knijnik DZ, Kapczinski F, Chachamovich E, Margis R, Eizirik CL: Psychodynamic group treatment for generalized social phobia. Rev Bras Psiquiatr 2004;26:77-81.

10 Stangier U, Heidenreich T, Peitz M, Lauterbach W, Clark DM: Cognitive therapy for social phobia: individual versus group treatment. Behav Res Ther 2003;41:991-1007.

11 Davidson JR, Foa EB, Huppert JD, Keefe FJ, Franklin ME, Compton JS, Zhao N, Connor KM, Lynch TR, Gadde KM: Fluoxetine, comprehensive cognitive behavioral therapy, and placebo in generalized social phobia. Arch Gen Psychiatry 2004;61:1005-1013.
12 Furmark T, Garpenstrand H, Marteinsdottir I, Langstrom B, Oreland L, Fredrikson M: Serotonin transporter polymorphism related to amygdala excitability and symptom severity in patients with social phobia. Neurosci Lett 2004;362:189-192.

13 Furmark T, Tillfors M, Marteinsdottir I, Fischer H, Pissiota A, Langstrom B, Fredrikson $\mathrm{M}$ : Common changes in cerebral blood flow in patients with social phobia treated with citalopram or cognitive-behavioral therapy. Arch Gen Psychiatry 2002;59:425433.

14 Stein MB, Philip R, Goldin MS, Sarren J, Eyler Zorilla LT, Brown GG: Increased amygdala activation to angry and contemptuous faces in generalized social phobia. Arch Gen Psychiatry 2002;59:1027-1034.

15 Leichsenring F: The efficacy of psychodynamic psychotherapy in specific psychiatric disorders: an update; in Stuart Ablon S, Levy R (eds): Evidence-Based Psychodynamic Psychotherapy. Totowa, Humana Press, 2007.

16 Bögels S, Tarrier N: Unexplored issues and future directions in social phobia research. Clin Psychol Rev 2004;24:731-736.

17 Mennin DS, Fresco DM, Heimberg RG, Schneier FR, Davies SO, Liebowitz MR: Screening for social anxiety disorder in the clinical setting using the Liebowitz Social Anxiety Scale. J Anxiety Disord 2002;16: 661-673.

18 Brown TA, di Nardo P, Barlow DH: Anxiety Disorders Interview Schedule Adult Version. Oxford, Oxford University Press, 1994.

19 Markgraf J: Diagnostisches Kurz-Interview bei Psychischen Störungen, Mini-DIPS. Berlin, Springer, 1994.

20 Gould RA, Buckminster S, Pollack MH, Otto MW, Yap L: Cognitive-behavioral and pharmacological treatment for social phobia: a meta-analysis. Clin Psychol Sci Pract 1997;4: 291-306.

21 Cohen J: Statistical Power Analysis for the Behavioral Sciences. Hillsdale, Erlbaum, 1988 .
22 Gelernter CS, Uhde TW, Cimbolic P, Arnkoff DB, Vittone BJ, Tancer ME, Bartko JJ: Cognitive-behavioral and pharmacological treatments of social phobia: a controlled study. Arch Gen Psychiatry 1991;48:938945.

23 Goisman RM, Warshaw MG, Keller MB: Psychosocial treatment prescriptions for generalized anxiety disorder, panic disorder, and social phobia. Am J Psychiatry 1999; 156: 1819-1821.

24 Clark D, Wells A: A cognitive model of social phobia; in Heimberg RG, Liebowitz MR, Hope DA, Schneider FR (eds): Social Phobia. Diagnosis, Assessment, Treatment. New York, Guilford, 1995, pp 69-93.

25 Willutzki U, Neumann B, Haas H, Koban C, Schulte D: Zur Psychotherapie sozialer Ängste - Kognitive Verhaltenstherapie im Vergleich zu einem kombiniert ressourcenorientierten Vorgehen: eine randomisierte kontrollierte Interventionsstudie. Z Klin Psychol Psychother 2004;33:42-50.

26 Heimberg RG, Salzmann DG, Holt CS, Blendell KA: Cognitive-behavioral group treatment for social phobia: effectiveness at five-year follow-up. Cogn Ther Res 1993;17: 325-339.

27 Clark D, Wells A: A Cognitive Model of Social Phobia. New York, Guilford, 1995.

28 Luborsky L: Principles of Psychoanalytic Psychotherapy. Manual for Supportive-Expressive Treatment. New York, Basic Book, 1984.

29 Leichsenring F, Leibing E: Supportive-expressive psychodynamic psychotherapy: an update. Curr Psychiatr Rev 2007;3:57-64.

30 Luborsky L: A guide to the CCRT method; in Luborsky L, Crits-Christoph P (eds): Understanding Transference. New York, Basic Books, 1990, pp 15-36.

31 Gabbard GO: Psychodynamics of panic disorder and social phobia. Bull Menninger Clin 1992;56(suppl A):A3-A13.

32 Hoffmann SO: Die Psychodynamik der sozialen Phobien: Eine Übersicht mit einem ersten 'Leitfaden' zur psychoanalytisch orientierten Psychotherapie. Forum Psychoanal 2002;18:51-71. 
33 Leichsenring F, Beutel M, Leibing E: A manual for short-term psychodynamic psychotherapy of social phobia. Bull Menninger Clin 2007;71:56-84.

34 Sholomskas DE, Syrakuse-Siewert G, Rounsaville BJ, Ball SA, Nuro KF, Carroll KM: We don't train in vain: a dissemination trial of three strategies of training clinicians in cognitive-behavioral therapy. J Consult Clin Psychol 2005;73:106-115.

35 Barber JP, Liese BS, Abrams MJ: Development of the cognitive therapy adherence and competence scale. Psychother Res 2003;13: 205-221.

36 Barber J, Crits-Christoph P: Development of a therapist adherence and competence rating scale for supportive-expressive dynamic psychotherapy. Psychother Res 1996;6:8194.

37 Hill CE, O'Grady KE, Elkin I: Applying the Collaborative Study Rating Scale to rate therapist adherence in cognitive-behavior therapy, interpersonal therapy, and clinical management. J Consult Clin Psychol 1992; 60:73-79.

38 Barber J, Crits-Christoph P: Development of a therapist adherence and competence rating scale for supportive-expressive dynamic psychotherapy. Psychother Res 1996;6:8194.

39 Waltz J, Addis ME, Koerner K, Jacobson NS: Testing the integrity of a psychotherapy procotol: assessment of adherence and competence. J Consult Clin Psychol 1993;61:620630.
40 Fava GA: The intellectual crisis of psychiatric research. Psychother Psychosom 2006;75: 202-208.

41 Hautzinger M, Bailer M, Woral H, Keller F: Beck-Depressionsinventar, ed 2. Göttingen, Hogrefe, 1995.

42 Chisholm D, Knudsen HC, Amaddeo F, Gaite L, van Wijngaarden B: Client SocioDemographic and Service Receipt Inventory - European Version: development of an instrument for international research. EPSILON Study 5. European Psychiatric Services: Inputs Linked to Outcome Domains and Needs. Br J Psychiatry Suppl 2000;39:S28S33.

43 Roick C, Kilian R, Matschinger H, Bernert S, Mory C, Angermeyer MC: German adaptation of the client sociodemographic and service receipt inventory - an instrument for the cost of mental health care. Psychiatr Prax 2001;28(suppl 2):S84-S90.

44 EuroQol Group: EuroQol - a new facility for the measurement of health-related quality of life. Health Policy 1990;16:199-208.

45 Von der Schulenburg JM, Claes C, Greiner W, Uber A: Die deutsche Version des EuroQol-Fragebogens. Z Gesundheitswiss 1998; 6:3-20.

46 Dolan P: Modeling valuations for EuroQol health states. Med Care 1997;35:1095-1108.

47 Deusinger IM: Frankfurter Selbstkonzept Skalen (FSKN). Göttingen, Huber, 1986.

48 Luborsky L, Barber J, Siqueland L, Johnson S, Najavits LM, Frank A, Daley D: The revised helping alliance questionnaire (HAQII). Psychometric properties. J Psychother Pract Res 1996;3:260-271.

49 Horowitz LM, Strauss B, Kordy H: Inventar zur Erfassung interpersonaler Probleme Deutsche Version - (IIP-D). Weinheim, Beltz, 1994.
50 Liebowitz MR: Social phobia. Mod Probl Pharmacopsychiatry 1987;22:141-173.

51 First MB, Spitzer RL, Gibbon M, Williams JB: Structured Clinical Interview for DSMIV Axis I Disorders (SCID), Clinician Version. Washington, American Psychiatric Press, 1996.

52 Brazier J, Roberts J, Deverill M: The estimation of a preference-based measure of health from the SF-36. J Health Econ 2002;21:271292

53 Bullinger M, Kirchberger I: SF-36. Fragebogen zum Gesundheitszustand. Göttingen, Hogrefe, 1998.

54 Beidel DC, Turner SM, Cooley MR: Assessing reliable and clinically significant change in social phobia: validity of the social phobia and anxiety inventory. Behav Res Ther 1993; 31:331-337.

55 Fydrich T: Soziale Phobie und Angstinventar (SPAI). Deutschsprachige Adaptation des 'Social Phobia and Anxiety Inventory' von Turner und Beidel. Göttingen, Hogrefe, 2003.

56 Kocherscheidt K, Fielder P, Kronmüller KT, Backstrass M, Mundt C: Zur empirischen Unterscheidung von Scham und Schuld: Beschreibung und Evaluierung der dt. Version der TOSCA. Z Differ Diagn Psychol 2002;23: 217-224.

57 Tangney JC: Assessing individual differences in proneness to shame and gult: development of the self-conscious affect and attribution inventory. J Pers Soc Psychol 1990;59: $102-111$.

\title{
Erratum
}

The correct institutional affiliations in the paper by Leichsenring et al., Psychother Psychosom 2009;78:35-41, should read:

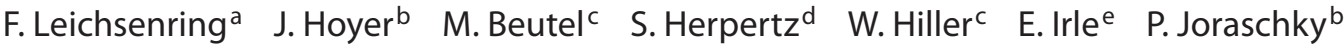 \\ $\begin{array}{llll}\text { H.H. König } & \text { T.M. de Liz } & \text { B. Nolting } & \text { d. K. Pöhlmann } \\ & \text { b. Salzer } & \text { H. Schauenburgh }\end{array}$

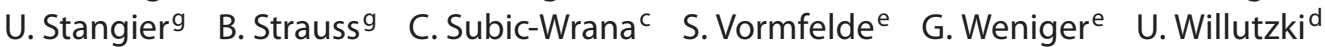 \\ J. Wiltink ${ }^{c}$ E. Leibing ${ }^{\mathrm{e}}$ \\ a University of Giessen, Giessen, ${ }^{b}$ University of Dresden, Dresden, ' $U$ niversity of Mainz, Mainz,

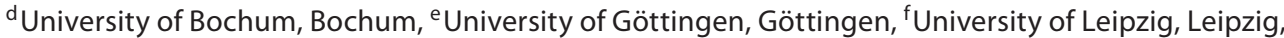 \\ gUniversity of Jena, Jena, h University of Heidelberg, Heidelberg, Germany
}

